Rev. Bras. Saúde Prod. Anim., Salvador, v.16, n.4, p.796-810 out../dez.., 2015 http://www.rbspa.ufba.br ISSN 15199940

\title{
Desempenho e digestibilidade de leitões alimentados com rações contendo feno de alfafa e frutoligossacarídeo na fase inicial ${ }^{1}$
}

\author{
Performance and digestibility of piglets fed with rations containing alfalfa hay and \\ fructooligosaccharide at the initial phase
}

\author{
BUDIÑO, Fábio Enrique Lemos ${ }^{2 *}$; PREZZI, Joel Alberto ${ }^{3}$; RODRIGUES, Daniela \\ Junqueira $^{3}$; MONFERDINI, Renato Pacheco ${ }^{3}$; OTSUK, Ivani Posar ${ }^{2}$
}

\footnotetext{
${ }^{1}$ Parte da dissertação de mestrado do segundo autor. FAPESP (09/06281-6).

${ }^{2}$ Agência Paulista de Tecnologia dos Agronegócios, Secretaria de Agricultura e Abastecimento, Instituto de Zootecnia, Nova Odessa, São Paulo, Brasil.

${ }^{3}$ Agência Paulista de Tecnologia dos Agronegócios, Secretaria de Agricultura e Abastecimento, Instituto de Zootecnia, Programa de Pós-Graduação em Produção Animal Sustentável, Nova Odessa, São Paulo, Brasil.

*Endereço para correspondência: fbudino@iz.sp.gov.br
}

\section{RESUMO}

Foram realizados dois ensaios, ambos utilizando delineamento em blocos casualizados em esquema fatorial $(3 \times 2)$, onde foram avaliados três níveis de inclusão de feno de alfafa $(0,0 \% ; 5,0 \%$ e $10,0 \%)$ e dois níveis de frutoligossacarídeo - FOS $(0,0 \%$ e $0,3 \%$ ). No Ensaio 1, com o objetivo de avaliar o desempenho zootécnico, foram utilizados 72 leitões desmamados, de linhagem comercial, de ambos os sexos (1 macho +1 fềmea/baia), seis repetições, com peso inicial de $5,95 \pm 0,73 \mathrm{~kg}$, com idade aproximada de 21 dias. Não foi observada interação entre os fatores estudados. No período dos 21 aos 59 dias de idade o ganho de peso não apresentou diferenças entre os tratamentos. O grupo que consumiu ração com adição de $0,3 \%$ de FOS apresentou maior consumo em relação ao grupo controle $(0,0 \%$ FOS $)$. Observou-se melhora na conversão alimentar das dietas que não possuíam inclusão de FOS, porém, não houve diferença significativa entre a dieta controle e as demais dietas em relação aos níveis de alfafa. No Ensaio 2 determinou-se a digestibilidade dos nutrientes, o balanço nitrogenado e as energias digestível e metabolizável das rações. Concluiu-se que a inclusão de FOS incrementou o consumo de dietas ricas em alfafa. A adição do feno de alfafa reduziu os coeficientes de digestibilidade dos nutrientes com exceção do extrato etéreo, porém não influenciou o balanço do nitrogênio

Palavras-chave: consumo de ração, conversão alimentar, ganho de peso, metabolismo, prebiótico

\section{SUMMARY}

Two assays were accomplished being, both using a randomized block design with factorial schema (3x2) where was evaluated three levels of inclusion of alfalfa hay $(0.0 \% ; 5.0 \%$ and $10.0 \%)$ and two levels of fructooligosaccharide - FOS $(0,0 \%$ and $0.3 \%)$. Assay 1 the aimed was to evaluate the performance, was utilized 72 piglets, commercial lineage, of both genders (one male + one female/cage), six reps with initial weight of $5.95 \pm 0.73 \mathrm{~kg}$, aged at approximately 21 days. There was no interaction between treatments. In the period from 21 to 59 days of age,, the gain of weight didn't show differences between treatments. The group that consumed ration with addition of $0.3 \%$ of FOS showed highest consumption in comparation with the control group $(0.0 \%$ FOS $)$. It was observe an improvement on the feed conversion of the diets that didn't have inclusion of FOS, however, it hadn't significant difference between the control diet and the others diets in relation to the levels of alfalfa. Assay 2 the objective was to determine the rations nutrients digestibility, nitrogen balance and the digestible and metabolizable energy. It was concluded that the addition of FOS enhances the consumption of diets with alfalfa hay. The addition of alfalfa hay reduced the digestibility coefficients of nutrients except for ether extract, but did not affect the nitrogen balance.

Keywords: consumption of ration, feed conversion, gain of weight, metabolism, prebiotic 


\section{INTRODUÇ̃̃O}

Os ingredientes alimentares, geralmente utilizados para favorecer $\mathrm{o}$ estabelecimento da saúde intestinal em leitões, como os derivados do leite e outros de origem animal, têm custo elevado e o uso de antibióticos, como promotores de crescimento têm sido restringidos na produção animal (ROBLES-HUAYNATE et al., 2013). Desta maneira, torna-se importante a busca por novas tecnologias ou ingredientes alimentares, capazes de contribuir para o funcionamento eficaz do trato gastrointestinal dos animais, favorecendo o bom desempenho (PASCOAL et al., 2012).

O suíno é considerado como animal nãoruminante de ceco não-funcional, ao contrário dos eqüinos, por exemplo, considerados de ceco funcional (BINDELE et al., 2008). Os componentes dietéticos da fibra são minimamente digeridos no intestino delgado de suínos, providenciando substrato para a fermentação microbiana no intestino grosso. Os principais produtos desta fermentação são os ácidos graxos de cadeia curta (AGCC).

A utilização de ingredientes fibrosos nas dietas pós desmame, pode ser responsável pela possível modulação da microbiota intestinal, já que a fração fibrosa não é digerida enzimaticamente, tornando-se disponível a fermentação microbiana no intestino grosso (MOLIST et al., 2009). Desta forma, os compostos que fazem parte da fibra dietética podem ser fermentados no intestino até se tornarem ácidos orgânicos, podendo assim aumentar a viscosidade da digesta intestinal, o que pode influenciar o desenvolvimento e o tamanho dos órgãos digestivos e a morfologia intestinal (SERENA et al., 2008).
Células do endotélio intestinal podem ser nutridas pelos AGCC derivados da fermentação bacteriana, sendo que a oxidação do butirato fornece mais que $70 \%$ do oxigênio consumido por este tecido em humanos e ratos. Além disso, o ácido láctico ou ácidos graxos produzidos provocam diminuição do $\mathrm{pH}$ do intestino grosso, que está relacionada com a inibição do crescimento de bactérias patogênicas e proporcionam melhores condições para o crescimento de microrganismos probióticos (McDONALD et al., 2006). Efeitos semelhantes são observados em animais ingerindo frutooligossacarídeo (BUDIÑO et al., 2010).

$\mathrm{O}$ objetivo deste estudo foi avaliar os efeitos individuais ou combinados do feno de alfafa e do prebiótico frutooligossacarídeo (FOS) na dieta de leitões desmamados, sobre o desempenho e a digestibilidade dos nutrientes e da energia.

\section{MATERIAL E MÉTODOS}

Foi conduzido no Setor de Suinocultura do Instituto de Zootecnia em Nova Odessa/SP. Foram utilizados 72 leitões, cruzados, de linhagem comercial, com peso inicial de $5,95 \pm 0,73 \mathrm{~kg}$, com idade média de 21 dias. Foi utilizado o delineamento em blocos casualizados, para controlar diferenças iniciais de peso, com seis tratamentos e seis repetições, em esquema fatorial $3 \times 2$ (três níveis de inclusão de feno de alfafa $\mathrm{x}$ dois níveis de inclusão de FOS), sendo que a unidade experimental foi constituída por dois animais (macho e fêmea) e o tratamento somente com ração basal (sem a presença do feno de alfafa) foi considerado controle.

Os animais, em grupos de dois (macho e fêmea) foram alojados em baias 
Rev. Bras. Saúde Prod. Anim., Salvador, v.16, n.4, p.796-810 out../dez.., 2015 http://www.rbspa.ufba.br

coletivas construídas em estrutura metálica, com piso plástico vazado, instalado a $80 \mathrm{~cm}$ do piso do galpão. As baias tinham a dimensão de $1,00 \mathrm{x}$ $2,00 \mathrm{~m}$, possuíam comedouros semiautomáticos e bebedouros do tipo chupeta.

Os tratamentos foram os seguintes: Ração Basal + 0\% de FOS; Ração Basal + 0,3\% de FOS; Ração com 5\% de Alfafa $+0 \%$ de FOS; Ração com 5\% de Alfafa + 0,3\% de FOS; Ração com 10\% de Alfafa $+0 \%$ de FOS; e Ração com $10 \%$ de Alfafa $+0,3 \%$ de FOS.

As dietas experimentais (Tabelas 1,2 e 3 ) foram formuladas de modo a atender as exigências nutricionais mínimas dos animais e pela composição nutricional dos alimentos apresentadas por Rostagno et al. (2011). Para a formulação das dietas foram consideradas três fases distintas: pré inicial (dos 21 aos 28 dias de idade), fase inicial 1 (dos 29 aos 42 dias de idade) e fase inicial 2 (dos 43 aos 59 dias de idade).

O desempenho dos leitões foi avaliado por meio de pesagens individuais dos animais, realizadas aos $21,28,42$ e 59 dias de idade, aonde foram aferidos o ganho de peso diário (GPD), o consumo diário de ração (CDR) e a conversão alimentar (CA). A ração foi fornecida à vontade $\mathrm{e}$ as sobras eram pesadas diariamente.

Para efeito de análise estatística foram considerados três períodos - Período 1 (21 a 28 dias de idade), Período 2 (21 a 42 dias de idade) e Período Total (21 a 59 dias de idade). Estes dados obtidos ocorreram em adequação para a análise de variância, sendo que os contrastes ortogonais observados foram controle $\mathrm{x}$ demais tratamentos (1) e alfafa $5 \% \mathrm{x}$ alfafa $10 \%(2)$.

Foi conduzido na sala de metabolismo animal do Setor de Suinocultura pertencente ao Instituto de
Zootecnia/APTA/SAA em Nova Odessa/SP.

Foram utilizados 24 suínos machos, provenientes do ensaio $1 \mathrm{com} 59$ dias de idade e pesando em média 26,55 \pm $2,12 \mathrm{~kg}$. O delineamento experimental utilizado foi o de blocos ao acaso em esquema fatorial ( $3 \times 2)$, com os mesmos seis tratamentos do Ensaio 1, e quatro repetições por tratamento. Foram escolhidos os quatro animais com pesos mais próximos a média de cada tratamento, mantidos individualmente em gaiolas de metabolismo por aproximadamente 11 dias (cinco de adaptação e seis de coleta). A metodologia utilizada foi a de coleta total de fezes e urina e utilizou o óxido férrico como marcador fecal (1\%).

Rações e fezes foram analisadas quanto à matéria seca (MS), proteína bruta (PB), fibras em detergente neutro (FDN) e ácido (FDA), extrato etéreo (EE), segundo Silva \& Queiróz (2002), e energia bruta (EB), em bomba calorimétrica do tipo Parr (AOAC, 1975). Na urina determinou-se o nitrogênio e a energia bruta, segundo metodologia de AOAC (1975). Os cálculos do coeficiente de digestibilidade da energia, dos nutrientes e de metabolizabilidade da energia foram realizados segundo Sakomura \& Rostagno (2007).

Os dados obtidos ocorreram em adequação para a análise de variância, sendo que os contrastes ortogonais observados foram controle $\mathrm{x}$ demais tratamentos (1) e alfafa $5 \%$ x alfafa $10 \%(2)$. 
Tabela 1. Composição percentual e níveis nutricionais das dietas: basal, alfafa (5\%) e alfafa (10\%) utilizadas na fase pré-inicial (21 a 28 dias de idade) dos leitões

\begin{tabular}{|c|c|c|c|}
\hline Ingredientes $(\%)^{*}$ & Basal & Alfafa 5 & Alfafa 10 \\
\hline Alfafa (Feno) & 0,000 & 5,000 & 10,000 \\
\hline Farelo de soja $46 \%$ & 20,000 & 17,000 & 16,600 \\
\hline Milho grão & 37,800 & 33,800 & 24,570 \\
\hline Açúcar & 2,000 & 2,000 & 2,000 \\
\hline Óleo de Soja & 0,200 & 2,000 & 6,500 \\
\hline Núcleo $^{* *}$ & 40,000 & 40,000 & 40,000 \\
\hline L-lisina $(\mathrm{HCl}, 78 \%)$ & 0,000 & 0,120 & 0,166 \\
\hline L-treonina $(98 \%)$ & 0,000 & 0,040 & 0,080 \\
\hline DL-metionina $(99 \%)$ & 0,000 & 0,040 & 0,085 \\
\hline Total & 100,000 & 100,000 & 100,000 \\
\hline \multicolumn{4}{|l|}{ Nutrientes calculados } \\
\hline Energia digestível (kcal/kg) & 3.267 & 3.200 & 3.225 \\
\hline Proteína bruta $(\%)$ & 20,822 & 20,095 & 20,148 \\
\hline Lisina digestível (\%) & 1,709 & 1,700 & 1,700 \\
\hline Metionina digestível (\%) & 0,634 & 0,644 & 0,663 \\
\hline Met + Cis digestível (\%) & 0,983 & 0,965 & 0,965 \\
\hline Treonina digestível (\%) & 1,091 & 1,063 & 1,063 \\
\hline Triptofano digestível (\%) & 0,263 & 0,240 & 0,240 \\
\hline Cálcio $(\%)$ & 0,621 & 0,684 & 0,754 \\
\hline Fósforo total (\%) & 0,619 & 0,603 & 0,600 \\
\hline Sódio $(\%)$ & 0,310 & 0,307 & 0,304 \\
\hline FDN total $(\%)$ & 6,280 & 7,590 & 8,820 \\
\hline Incremento FDN fornecido pela alfafa $(\%)$ & 0,000 & 1,940 & 3,880 \\
\hline
\end{tabular}

*O frutoligossacarídeo foi incluído em substituição ao milho, nos tratamentos em que foi testado.

**Níveis de garantia por kg de ração: Vit. A - 3.0000 U.I.; Vit. D3 - 5500 U.I.; Vit. E - 187.5 mg; Vit. K3 - 12,5 mg; Vit. B1 - 5,0 mg; Vit. B2 - 12,50 mg; Vit. B6 7,50 mg; Vit. B12 - 100 mcg; Ac. Fólico - $1 \mathrm{mg}$; Ác. Pantotênico - 75 mg; Niacina - 125 mg; Biotina - 0,75 mg; Colina - 3000 mg; Cálcio (max) - 21 g; Fósforo (min) - 12,20 g; Flúor (max) - 122 mg; Sódio - 5,5g; Ferro - 250 mg; Cobre - 30 mg; Zinco - 250 mg; Manganês - 100 mg; Iodo - 2,48 mg; Selênio - 1 mg; Cobalto - 1,88 mg; PB (min) - 18\%; Lisina - 16000 mg; Metionina - 7200 mg; Treonina - 106036 mg; Lactose (min) - 20\%; Palatabilizante - 500 mg; Flavorizante - 0,05\%; $\mathrm{EM}-3000 \mathrm{kcal} / \mathrm{kg}$; Antioxidante $-0,025 \%$. 
Tabela 2. Composição percentual e níveis nutricionais das dietas: basal, alfafa (5\%) e alfafa (10\%) utilizadas na fase inicial 1 (29 a 42 dias de idade) dos leitões

\begin{tabular}{|c|c|c|c|}
\hline Ingredientes (\%) & Basal & Alfafa 5 & Alfafa 10 \\
\hline Alfafa (Feno) & 0,000 & 5,000 & 10,000 \\
\hline Farelo de soja $46 \%$ & 29,000 & 25,600 & 25,400 \\
\hline Milho grão & 47,900 & 42,910 & 34,710 \\
\hline Açúcar & 2,000 & 2,000 & 2,000 \\
\hline Óleo de Soja & 1,100 & 4,300 & 7,600 \\
\hline Núcleo $^{* *}$ & 20,000 & 20,000 & 20,000 \\
\hline L-lisina $(\mathrm{HCl}, 78 \%)$ & 0,000 & 0,011 & 0,015 \\
\hline L-treonina $(98 \%)$ & 0,000 & 0,040 & 0,070 \\
\hline DL-metionina $(99 \%)$ & 0,000 & 0,040 & 0,070 \\
\hline Total & 100,000 & 100,000 & 100,000 \\
\hline \multicolumn{4}{|l|}{ Nutrientes calculados } \\
\hline Energia digestível (kcal/kg) & 3.337 & 3.318 & 3.304 \\
\hline Proteína bruta $(\%)$ & 21,341 & 21,364 & 21,532 \\
\hline Lisina digestível (\%) & 1,529 & 1,500 & 1,500 \\
\hline Metionina digestível (\%) & 0,561 & 0,565 & 0,581 \\
\hline Met + Cis digestível (\%) & 0,898 & 0,880 & 0,880 \\
\hline Treonina digestível (\%) & 1,000 & 0,980 & 0,980 \\
\hline Triptofano digestível (\%) & 0,280 & 0,254 & 0,255 \\
\hline Cálcio $(\%)$ & 0,728 & 0,790 & 0,860 \\
\hline Fósforo total (\%) & 0,610 & 0,590 & 0,590 \\
\hline Sódio $(\%)$ & 0,190 & 0,186 & 0,183 \\
\hline FDN total $(\%)$ & 8,440 & 11,270 & 10,860 \\
\hline Incremento FDN fornecido pela alfafa $(\%)$ & 0,000 & 1,940 & 3,880 \\
\hline
\end{tabular}

Incremento FDN fornecido pela alfafa $(\%)$

que foi testado.

**Níveis de garantia por kg de ração: Vit. A - 60.000 U.I.; Vit. D3 - 11000 U.I.; Vit. E - 375mg; Vit. K3 - 25 mg; Vit. B1 - 10,0 mg; Vit. B2 - 25,0 mg; Vit. B6 15,00 mg; Vit. B12 - 200 mcg; Ac.Fólico - 2 mg; Ác.Pantotenico - 150 mg; Niacina - 250 mg; Biotina - 1,50 mg; Colina - 4000 mg; Cálcio (max) - 43,75 g; Fósforo (min) - 21,25 g; Sódio - 10,0 g; Ferro - 500 mg; Cobre - 57,50 mg; Zinco - 500 mg; Manganês - 300 mg; Iodo - 3,875 mg; Selênio - 1 mg; Cobalto - 3,75 mg; PB(min) - 21\%; Lisina - 16250 mg; Metionina - $11250 \mathrm{mg}$; Treonina - $13500 \mathrm{mg}$; Lactose (min) - 20\%; Sacarina sódica (min) - 0,04\%; Palatabilizante - 500 mg; Ác.Fórmico (min) - 0,0085\%; Ác.Fosfórico (min) - 0,0145\%; Zinco - 500mg. 
Tabela 3. Composição percentual e níveis nutricionais das dietas: basal, alfafa (5\%) e alfafa (10\%) utilizadas na fase inicial 2 (43 a 59 dias de idade) dos leitões

\begin{tabular}{|c|c|c|c|}
\hline Ingredientes $(\%)^{*}$ & Basal & Alfafa 5 & Alfafa 10 \\
\hline Alfafa (Feno) & 0,000 & 5,000 & 10,000 \\
\hline Farelo de soja $46 \%$ & 29,600 & 30,000 & 30,200 \\
\hline Milho grão & 63,195 & 56,390 & 48.188 \\
\hline Açúcar & 2,000 & 2,000 & 2,000 \\
\hline Óleo de Soja & 1,000 & 2,400 & 5,300 \\
\hline Núcleo** & 4,000 & 4,000 & 4,000 \\
\hline L-lisina $(\mathrm{HCl}, 78 \%)$ & 0,020 & 0,010 & 0,047 \\
\hline L-treonina $(98 \%)$ & 0,015 & 0,020 & 0,055 \\
\hline DL-metionina (99\%) & 0,170 & 0,180 & 0,210 \\
\hline Total & 100,000 & 100,000 & 100,000 \\
\hline \multicolumn{4}{|l|}{ Nutrientes calculados } \\
\hline Energia digestível (kcal/kg) & 3.409 & 3.355 & 3.302 \\
\hline Proteína bruta $(\%)$ & 19,900 & 20,218 & 20,360 \\
\hline Lisina digestível (\%) & 1,280 & 1,280 & 1,280 \\
\hline Metionina digestível (\%) & 0,547 & 0,547 & 0,562 \\
\hline Met + Cis digestível (\%) & 0,877 & 0,871 & 0,870 \\
\hline Treonina digestível (\%) & 0,800 & 0,800 & 0,800 \\
\hline Triptofano digestível (\%) & 0,254 & 0,254 & 0,245 \\
\hline Cálcio (\%) & 0,820 & 0,893 & 0,962 \\
\hline Fósforo total (\%) & 0,593 & 0,592 & 0,583 \\
\hline Sódio $(\%)$ & 0,185 & 0,184 & 0,181 \\
\hline FDN total $(\%)$ & 9,900 & 11,340 & 12,530 \\
\hline Incremento FDN fornecido pela alfafa (\%) & 0,000 & 1,940 & 3,880 \\
\hline
\end{tabular}

*O frutoligossacarídeo foi incluído em substituição ao milho, nos tratamentos em que foi testado;

**Níveis de garantia por kg de ração: Vit. A - 262500U.I.; Vit. D3 - 55000 U.I.; Vit. E - 1,875 mg; Vit. K3 - 100 mg; Vit. B1 - 50,0 mg; Vit. B2 - 125,0 mg; Vit. B6 - 75,00 mg; Vit. B12 - 1 mcg; Ac. Fólico - 10 mg; Ác. Pantotenico - 500 mg; Niacina - 1000 mg; Biotina - 5,0 mg; Colina - 10000 mg; Cálcio (max) - 183 g; Fósforo (min) - 67 g; Sódio - 36 g; Ferro - 2000 mg; Cobre - 000 mg; Zinco - 2250 mg; Manganês - 875 mg; Iodo - 17,5 mg; Selênio - 8,75 mg; Cobalto - 16,25 mg; Lisina - $7000 \mathrm{mg}$; Metionina - $5000 \mathrm{mg}$; Palatabilizante; 0,063\%; Anti-oxidante - 0,125\%. 
Rev. Bras. Saúde Prod. Anim., Salvador, v.16, n.4, p.796-810 out../dez.., 2015 http://www.rbspa.ufba.br

\section{RESULTADOS E DISCUSSÃO}

Observou-se que no período de 21 a 28 dias de idade as diferenças $(\mathrm{P}<0,05)$ entre os tratamentos para o GPD ocorreram dentro do grupo suplementado com FOS, sendo que os leitões alimentados com a combinação ração basal $+0,3 \%$ FOS apresentaram o maior GPD (Tabela 4). No período de 21 a 28 dias de idade verificou-se, dentro do grupo sem adição de FOS, maior GPD $(\mathrm{P}<0,05)$ para os leitões que consumiram a ração basal em relação aos grupos com acesso a alfafa. No período de 21 a 28 dias de idade, nas rações com inclusão de FOS observouse maior GPD $(\mathrm{P}<0,05)$ nos leitões consumindo ração com $5 \%$ de alfafa em relação aos que consumiram com $10 \%$. Quando analisamos o período total não verificamos diferenças $(\mathrm{P}>0,05)$ entre os tratamentos (Tabela 4).

Tabela 4. Médias corrigidas e erros padrão das médias para o ganho de peso diário (g/animal) de leitões alimentados com três níveis de inclusão de feno de alfafa $(0,0 \%, 5,0 \%$ e $10,0 \%)$ e dois níveis de FOS $(0,0 \%$ e $0,3 \%)$ no Período 1 (21-28 dias de idade), Período 2 (21-42 dias de idade) e Período Total (21-59 dias de idade)

\begin{tabular}{|c|c|c|c|c|c|c|}
\hline \multirow{2}{*}{ FOS } & \multicolumn{3}{|c|}{ Alfafa } & & \multicolumn{2}{|c|}{ Contraste } \\
\hline & $0,0 \%$ & $5,0 \%$ & $10,0 \%$ & Média & (1) & (2) \\
\hline \multicolumn{7}{|c|}{ Período 1} \\
\hline $0,0 \%$ & $119,28 \pm 15,71$ & $109,28 \pm 15,71$ & $106,42 \pm 15,71$ & $111,42 \pm 9,28$ & ns & ns \\
\hline $0,3 \%$ & $164,28 \pm 15,71$ & $122,85 \pm 15,71$ & $100,7 \pm 15,71$ & $129,28 \pm 9,28$ & $*$ & ns \\
\hline Média & $141,42 \pm 11,42$ & $116,42 \pm 11,42$ & $103,57 \pm 11,42$ & - & ns & ns \\
\hline \multicolumn{7}{|c|}{ Período 2} \\
\hline $0,0 \%$ & $278,80 \pm 15,47$ & $237,14 \pm 15,47$ & $235,95 \pm 15,47$ & $250,47 \pm 9,04$ & $*$ & ns \\
\hline $0,3 \%$ & $262,38 \pm 15,47$ & $255,71 \pm 15,47$ & $199,52 \pm 15,47$ & $239,28 \pm 9,04$ & $\mathrm{~ns}$ & $*$ \\
\hline Média & $270,47 \pm 10,95$ & $246,42 \pm 10,95$ & $217,85 \pm 10,95$ & - & & \\
\hline \multicolumn{7}{|c|}{ Período Total } \\
\hline $0,0 \%$ & $429,60 \pm 21,97$ & $406,05 \pm 21,97$ & $393,68 \pm 21,97$ & $409,73 \pm 12,63$ & ns & ns \\
\hline $0,3 \%$ & $442,63 \pm 21,97$ & $434,34 \pm 21,97$ & $379,73 \pm 21,97$ & $418,94 \pm 12,63$ & ns & ns \\
\hline Média & $436,05 \pm 15,52$ & $420,13 \pm 15,52$ & $386,71 \pm 15,52$ & - & ns & ns \\
\hline
\end{tabular}

ns - não significativo; * significativo a 5\%; (1) Controle X Demais; (2) Alfafa 5\% X Alfafa 10\%.

Em relação ao CDR (Tabela 5), no período 1 dentro dos grupos suplementados com FOS verificou-se maior $(\mathrm{P}<0,05) \quad \mathrm{CDR}$ nos leitões alimentados com ração basal seguidos dos consumindo rações com $5 \%$ e $10 \%$ de alfafa, respectivamente. Este mesmo fenômeno foi observado no período 2 mas agora dentro dos grupos não suplementados com FOS. Além disso, observou-se maior CDR nos tratamentos adicionados de FOS dentro dos grupos que tiveram acesso a alfafa.
Quando se analisou o período total, dentro dos grupos sem a adição de FOS, observou-se maior $(\mathrm{P}<0,01) \mathrm{CDR}$ nos leitões com acesso a ração basal seguidos dos consumindo rações com $10 \%$ e $5 \%$ de alfafa, respectivamente. Já quando foram analisados os grupos com adição de FOS verificou-se maior $(\mathrm{P}<0,01) \mathrm{CDR}$ nos leitões consumindo $10 \%$ de alfafa, seguidos dos que consumiram $5 \%$ e ração basal, respectivamente. Além disso, também se observou maior $(\mathrm{P}<0,05) \mathrm{CDR}$ nos 
Rev. Bras. Saúde Prod. Anim., Salvador, v.16, n.4, p.796-810 out../dez.., 2015 http://www.rbspa.ufba.br

tratamentos adicionados de FOS quando comparados aos grupos sem a adição do prebiótico.

Não houve diferenças significativas $(\mathrm{P}>0,05)$ entre os tratamentos para $\mathrm{CA}$ no período 1 (Tabela 6 ).

No período 2 verificou-se melhor CA $(\mathrm{P}<0,05)$ nos leitões consumindo ração basal $+0,3 \%$ FOS seguidos dos tratamentos com alfafa $5 \%$ e alfafa $10 \%$, respectivamente. Sendo que a CA do grupo que consumiu ração com $10 \%$ de alfafa foi melhor $(\mathrm{P}<0,05)$ na ausência do prebiótico. Ao analisar o período total observou-se diferença significativa $(\mathrm{P}<0,05)$ na $\mathrm{CA}$ entre os tratamentos que consumiram alfafa, dentro do grupo com a presença do FOS. Além disso, ao comparar as médias entre os grupos com e sem a presença do FOS verificou-se melhores valores $(\mathrm{P}<0,05)$ na ausência deste.

Existe certa disparidade de resultados em relação ao desempenho de leitões alimentados com fontes de fibra nas dietas e isto pode ser devido às características químicas e físicas de cada fonte e de seu grau de lignificação, além da quantidade de inclusão na ração. A capacidade dos suínos em utilizar rações contendo fibra dietética aumenta consideravelmente à medida que o animal se desenvolve devido ao maior tamanho do trato gastrointestinal, em especial do intestino grosso, e consequentemente devido à maior população microbiana (bactérias celulolíticas) encontradas no ceco (PASCOAL et al, 2012).

Os suínos, em particular os animais na fase adulta (151-185 dias de idade), mesmo quando alimentados com elevados níveis de fibra dietética, são capazes de manter o GPD em índices adequados devido à sua capacidade de elevação do consumo, como tentativa de manter estável o nível de energia digestível ingerida (BINDELE et al, 2008).

Tabela 5. Médias corrigidas e erros padrão das médias para o consumo diário de ração (g/animal) para leitões alimentados com três níveis de inclusão de feno de alfafa $(0,0 \%, 5,0 \%$ e $10,0 \%)$ e dois níveis de FOS $(0,0 \%$ e $0,3 \%)$ no Período 1 (21-28 dias de idade), Período 2 (21-42 dias de idade) e Período Total (2159 dias de idade)

\begin{tabular}{|c|c|c|c|c|c|c|}
\hline \multirow{2}{*}{ FOS } & \multicolumn{3}{|c|}{ Alfafa } & \multicolumn{3}{|c|}{ Contraste } \\
\hline & $0,0 \%$ & $5,0 \%$ & $10,0 \%$ & Média & (1) & (2) \\
\hline \multicolumn{7}{|c|}{ Período 1} \\
\hline $0,0 \%$ & $213,57 \pm 15,71$ & $205,71 \pm 15,71$ & $173,57 \pm 15,71$ & $197,85 \pm 9,28$ & $\mathrm{~ns}$ & ns \\
\hline $0,3 \%$ & $249,28 \pm 15,71$ & $222,85 \pm 15,71$ & $172,14 \pm 15,71$ & $214,28 \pm 9,28$ & $*$ & $*$ \\
\hline Média & $231,42 \pm 11,42$ & $214,28 \pm 11,42$ & $172,85 \pm 11,42$ & - & ns & ns \\
\hline \multicolumn{7}{|c|}{ Período 2} \\
\hline $0,0 \%$ & $405,95 \pm 5,23$ & $377,14 \pm 5,23^{\mathrm{B}}$ & $360,95 \pm 5,23^{\mathrm{B}}$ & $381,42 \pm 3,09$ & $* *$ & $*$ \\
\hline $0,3 \%$ & $400,23 \pm 5,23$ & $412,38 \pm 5,23^{\mathrm{A}}$ & $406,19 \pm 5,23^{\mathrm{A}}$ & $406,19 \pm 3,09$ & ns & $\mathrm{ns}$ \\
\hline Média & $403,09 \pm 3,80$ & $394,76 \pm 3,80$ & $383,57 \pm 3,80$ & - & ns & ns \\
\hline \multicolumn{7}{|c|}{ Período Total } \\
\hline $0,0 \%$ & $700,65 \pm 2,89^{\mathrm{B}}$ & $610,00 \pm 2,89^{\mathrm{B}}$ & $682,23 \pm 2,89^{\mathrm{B}}$ & $664,34 \pm 1,71$ & $* *$ & $* *$ \\
\hline $0,3 \%$ & $744,21 \pm 2,89^{\mathrm{A}}$ & $747,76 \pm 2,89^{\mathrm{A}}$ & $761,71 \pm 2,89^{\mathrm{A}}$ & $751,18 \pm 1,71$ & $* *$ & $* *$ \\
\hline Média & $722,36 \pm 2,10$ & $678,81 \pm 2,10$ & $721,97 \pm 2,10$ & - & $\mathrm{ns}$ & ns \\
\hline
\end{tabular}

ns - não significativo; **significativo a 1\%; *significativo a 5\%; (1) Controle X Demais; (2) Alfafa

$5 \%$ X Alfafa $10 \% ;{ }^{\mathrm{A}, \mathrm{B}}$ Médias seguidas da mesma letra na coluna, não diferem entre si pelo teste $\mathrm{F}$ $(\mathrm{P}<0,05)$ 
Rev. Bras. Saúde Prod. Anim., Salvador, v.16, n.4, p.796-810 out../dez.., 2015 http://www.rbspa.ufba.br ISSN 15199940

Tabela 6. Médias corrigidas e erros padrão das médias para a conversão alimentar de leitões alimentados com três níveis de inclusão de feno de alfafa $(0,0 \%, 5,0 \%$ e $10,0 \%)$ e dois níveis de FOS $(0,0 \%$ e $0,3 \%)$ no Período 1 (21-28 dias de idade), Período 2 (21-42 dias de idade) e Período Total (21-59 dias de idade)

\begin{tabular}{|c|c|c|c|c|c|c|}
\hline \multirow{2}{*}{ FOS } & \multicolumn{3}{|c|}{ Alfafa } & \multicolumn{3}{|c|}{ Contraste } \\
\hline & $0,0 \%$ & $5,0 \%$ & $10,0 \%$ & Média & (1) & (2) \\
\hline & & Período 1 & & & & \\
\hline $0,0 \%$ & $2,41 \pm 0,35$ & $1,89 \pm 0,35$ & $1,66 \pm 0,35$ & $1,99 \pm 0,20$ & ns & ns \\
\hline $0,3 \%$ & $1,55 \pm 0,35$ & $2,17 \pm 0,35$ & $1,98 \pm 0,35$ & $1,90 \pm 0,20$ & ns & ns \\
\hline \multirow[t]{2}{*}{ Média } & $1,98 \pm 0,25$ & $2,03 \pm 0,25$ & $1,81 \pm 0,25$ & & $\mathrm{~ns}$ & ns \\
\hline & & Período 2 & & & & \\
\hline $0,0 \%$ & $1,47 \pm 0,13$ & $1,59 \pm 0,13$ & $1,56 \pm 0,13^{\mathrm{B}}$ & $1,54 \pm 0,07$ & ns & ns \\
\hline $0,3 \%$ & $1,55 \pm 0,13$ & $1,64 \pm 0,13$ & $2,20 \pm 0,13^{\mathrm{A}}$ & $1,79 \pm 0,07$ & $*$ & $* *$ \\
\hline \multirow[t]{2}{*}{ Média } & $1,51 \pm 0,09$ & $1,61 \pm 0,09$ & $1,88 \pm 0,09$ & & ns & ns \\
\hline & & Período Tota & & & & \\
\hline $0,0 \%$ & $1,64 \pm 0,10$ & $1,51 \pm 0,10$ & $1,76 \pm 0,10$ & $1,64 \pm 0,06^{\mathrm{B}}$ & ns & ns \\
\hline $0,3 \%$ & $1,72 \pm 0,10$ & $1,72 \pm 0,10$ & $2,07 \pm 0,10$ & $1,84 \pm 0,06^{\mathrm{A}}$ & ns & $*$ \\
\hline Média & $1,68 \pm 0,07$ & $1,62 \pm 0,07$ & $1,92 \pm 0,07$ & & ns & ns \\
\hline
\end{tabular}

ns - não significativo; $* *$ significativo a $1 \%$; $*$ significativo a 5\%; (1) Controle X Demais; (2) Alfafa 5\% $\mathrm{X}$ Alfafa $10 \%$; ${ }^{\mathrm{A}, \mathrm{B}}$ Médias seguidas da mesma letra na coluna, não diferem entre si pelo teste $\mathrm{F}(\mathrm{P}<0,05)$.

No presente estudo notou-se que houve aumento gradativo no CDR do grupo que recebeu a ração com maior inclusão de feno de alfafa (10\%), sendo que ao final do período experimental estes não apresentaram diferenças significativas $(\mathrm{P}>0,05)$ em relação ao $\mathrm{CDR}$ e GPD quando comparados aos outros grupos $(0 \%$ e $5 \%$ de alfafa), fato este que demonstra uma provável adaptação do sistema digestório destes leitões. Longland et al. (1994) relata que apesar do baixo aproveitamento nutricional das fibras, é possível observar propriedades benéficas, sendo uma delas o estímulo ao desenvolvimento do trato digestório dos leitões.

Huo (1993) também verificou aumento no CDR, possivelmente para equilibrar a diminuição da energia digestível causada pela adição de fibra na forma de casca e farelo de arroz na dieta de leitões. Molist et al. (2009) avaliaram rações contendo farelo de trigo ou polpa de beterraba, e notaram que nos primeiros dez dias pós desmame, os animais que receberam a dieta contendo o farelo de trigo, apresentaram maior CDR quando comparados aos que ingeriram a dieta sem inclusão de fonte de fibra, porém não verificaram diferenças para o GPD e a CA.

Entretanto, Gomes et al. (2008) verificaram que a inclusão de fibra na ração de suínos em fase de recria promoveu redução no $\mathrm{CDR}$, sem interferir negativamente no GPD. A conversão alimentar foi similar entre os tratamentos, evidenciando que, mesmo na fase inicial de desenvolvimento, o desempenho de leitões não sofre prejuízos severos com a inclusão de uma fonte de fibra alimentar (feno de Tifton).

Högberg \& Lindberg (2004) verificaram incrementos no GPD de leitões desmamados, quando receberam maiores quantidades de fibra (triticale, trigo, aveia e cevada) nas dietas, porém relataram que este acréscimo no GPD 
Rev. Bras. Saúde Prod. Anim., Salvador, v.16, n.4, p.796-810 out../dez.., 2015 http://www.rbspa.ufba.br

está relacionado ao aumento dos pesos dos órgãos.

Em relação à utilização do FOS, no presente estudo, verificou-se incremento $(\mathrm{P}<0,05)$ no $\mathrm{CDR}$ em todos os tratamentos na presença deste prebiótico, o que influenciou diretamente os valores da $\mathrm{CA}(\mathrm{P}<0,05)$ quando foram comparados os tratamentos com e sem FOS considerando o período total, mas isto não promoveu uma alteração significativa $(\mathrm{P}>0,05)$ no GPD.

Os mecanismos envolvidos, os quais podem influenciar o CDR, ainda não estão totalmente elucidados, mas alguns fatores podem estar envolvidos como palatabilidade e textura, entre outros. Uma possibilidade é a de que o FOS pode ter efeitos benéficos sobre a saúde do trato gastrointestinal por estabilizar a microbiota em leitões recémdesmamados, ocorrendo menos distúrbios alimentares o que poderia aumentar o CDR (BUDIÑO et al., 2010).

Outras pesquisas não verificaram diferenças no CDR entre leitões suplementados com FOS e/ou promotor de crescimento contra uma dieta basal (MIKKELSEN et al., 2003) e entre leitões suplementados com 7,5 ou $15 \mathrm{~g}$ de FOS por kg de ração durante a fase de creche (HOUDIJK et al., 1998).

Budiño et al. (2006), observaram que dos 50 aos 70 dias de idade, os maiores $(\mathrm{P}<0,05)$ GPD foram observados em leitões que receberam ração contendo FOS $(0,2 \%)$ e os menores nos animais que receberam rações com antibiótico (40ppm) e probiótico $(0,04 \%)$, enquanto que dos 21 aos 70 dias de idade os melhores GPD foram obtidos pelos leitões recebendo dietas contendo FOS e simbiótico e os piores naqueles tratados com antibiótico. Resultados de desempenhos favoráveis com a suplementação com FOS na ração de leitões também foram obtidos por He et al. (2002).

$\mathrm{Na}$ Tabela 7 estão apresentados os resultados dos coeficientes de digestibilidade da matéria seca (CDMS), proteína bruta (CDPB), extrato etéreo (CDEE), fibra em detergente neutro (CDFDN), fibra em detergente ácido (CDFDA) e energia bruta (CDEB), além do coeficiente de metabolizabilidade da energia bruta (CMEB) e os dados do balanço nitrogenado das dietas.

A inclusão de feno de alfafa à dieta afetou negativamente $(\mathrm{P}<0,05)$ os coeficientes de digestibilidade de alguns nutrientes (MS, PB, FDN, FDA e EB), concordando com dados obtidos por Gomes et al. (2008), que estudando incremento de $8 \%$ de FDN na ração de suínos na fase de crescimento verificaram reduções significativas $(\mathrm{P}<0,01)$ na digestibilidade da matéria seca, energia bruta, proteína bruta e fibra em detergente neutro e também com Santos et al. (2005) que constataram que os altos teores em fibra bruta nos alimentos testados (farelo de palma, farelo de trigo, farelo de babaçu e farelo de polpa cítrica) influenciaram os valores de coeficiente de digestibilidade da proteína bruta assim como resultaram em menores valores de ED e EM, resultado também encontrado no presente estudo.

A fibra alimentar pode ocasionar redução na digestibilidade dos nutrientes em virtude do aumento da taxa de passagem pelo trato gastrointestinal, da maior excreção de nitrogênio metabólico e microbiano e pela baixa disponibilidade de nitrogênio e outros nutrientes da fibra (GOMES et al., 2008). 
Tabela 7. Médias dos coeficientes aparentes de digestibilidade (CD), metabolizabilidade (CM) e balanço nitrogenado das dietas com três níveis de inclusão de feno de alfafa $(0 \%, 5 \%$ e $10 \%)$ e dois níveis de frutoligossacarídeo $(0,0 \%$ e $0,3 \%)$

\begin{tabular}{|c|c|c|c|c|c|c|}
\hline \multirow{2}{*}{ FOS } & \multicolumn{3}{|c|}{ Alfafa } & \multirow{2}{*}{ Média } & \multicolumn{2}{|c|}{ Contraste } \\
\hline & $0,0 \%$ & $5,0 \%$ & $10,0 \%$ & & (1) & (2) \\
\hline & & CDMS (\%) & & & & \\
\hline $0,0 \%$ & $71,51 \pm 2,19$ & $63,94 \pm 2,19$ & $55,38 \pm 2,19$ & $63,61 \pm 1,26$ & $* *$ & $*$ \\
\hline $0,3 \%$ & $70,60 \pm 2,19$ & $64,13 \pm 2,19$ & $56,68 \pm 2,19$ & $63,80 \pm 1,26$ & $* *$ & $*$ \\
\hline \multirow[t]{2}{*}{ Média } & $71,05 \pm 1,55$ & $64,04 \pm 1,55$ & $56,03 \pm 1,55$ & & $\mathrm{~ns}$ & ns \\
\hline & & CDPB (\%) & & & & \\
\hline $0,0 \%$ & $73,28 \pm 1,81$ & $67,18 \pm 1,81$ & $63,90 \pm 1,81$ & $68,12 \pm 1,04$ & $* *$ & ns \\
\hline $0,3 \%$ & $74,45 \pm 1,81$ & $67,54 \pm 1,81$ & $65,25 \pm 1,81$ & $69,08 \pm 1,04$ & $* *$ & ns \\
\hline \multirow[t]{2}{*}{ Média } & $73,86 \pm 1,28$ & $67,36 \pm 1,28$ & $64,57 \pm 1,28$ & & ns & ns \\
\hline & & CDEE (\%) & & & & \\
\hline $0,0 \%$ & $51,71 \pm 3,41^{\mathrm{A}}$ & $66,16 \pm 3,41^{\mathrm{A}}$ & $69,81 \pm 3,41^{\mathrm{A}}$ & $62,56 \pm 1,97$ & $* *$ & ns \\
\hline $0,3 \%$ & $32,67 \pm 3,41^{\mathrm{B}}$ & $40,10 \pm 3,41^{\mathrm{B}}$ & $68,30 \pm 3,41^{\mathrm{A}}$ & $47,07 \pm 1,97$ & $* *$ & $* *$ \\
\hline \multirow[t]{2}{*}{ Média } & $42,19 \pm 2,41$ & $53,13 \pm 2,41$ & $69,05 \pm 2,41$ & & ns & ns \\
\hline & & CDFDN (\%) & & & & \\
\hline $0,0 \%$ & $33,53 \pm 8,41$ & $16,00 \pm 8,41$ & $8,43 \pm 8,41$ & $19,32 \pm 4,85$ & ns & ns \\
\hline $0,3 \%$ & $36,43 \pm 8,41$ & $13,22 \pm 8,41$ & $1,76 \pm 8,41$ & $17,14 \pm 4,85$ & $*$ & ns \\
\hline \multirow[t]{2}{*}{ Média } & $34,98 \pm 5,95$ & $14,61 \pm 5,95$ & $5,10 \pm 5,95$ & & ns & ns \\
\hline & & CDFDA $(\%)$ & & & & \\
\hline $0,0 \%$ & $44,50 \pm 9,80$ & $26,13 \pm 9,80$ & $-1,73 \pm 9,80$ & $22,97 \pm 5,66$ & $*$ & ns \\
\hline $0,3 \%$ & $44,67 \pm 9,80$ & $14,38 \pm 9,80$ & $-3,87 \pm 9,80$ & $18,39 \pm 5,66$ & $* *$ & ns \\
\hline \multirow[t]{2}{*}{ Média } & $44,58 \pm 6,93$ & $20,25 \pm 6,93$ & $-2,80 \pm 6,25$ & & ns & ns \\
\hline & & CDEB (\%) & & & & \\
\hline $0,0 \%$ & $70,03 \pm 2,18$ & $62,99 \pm 2,18$ & $55,41 \pm 2,18$ & $62,81 \pm 1,26$ & $* *$ & $*$ \\
\hline $0,3 \%$ & $68,98 \pm 2,18$ & $62,84 \pm 2,18$ & $56,90 \pm 2,18$ & $62,91 \pm 1,26$ & $* *$ & ns \\
\hline \multirow[t]{2}{*}{ Média } & $69,51 \pm 1,54$ & $62,92 \pm 1,54$ & $56,16 \pm 1,54$ & & $\mathrm{~ns}$ & ns \\
\hline & & CMEB (\%) & & & & \\
\hline $0,0 \%$ & $66,83 \pm 2,21$ & $60,25 \pm 2,21$ & $52,89 \pm 2,21$ & $59,99 \pm 1,28$ & $* *$ & $*$ \\
\hline $0,3 \%$ & $65,65 \pm 2,21$ & $59,81 \pm 2,21$ & $54,38 \pm 2,21$ & $59,94 \pm 1,28$ & $* *$ & ns \\
\hline Média & $66,23 \pm 1,56$ & $60,03 \pm 1,56$ & $53,64 \pm 1,56$ & & ns & ns \\
\hline
\end{tabular}




\begin{tabular}{|c|c|c|c|c|c|c|}
\hline & & $\mathrm{ED}(\mathrm{kcal} / \mathrm{kg})$ & & & & \\
\hline $0,0 \%$ & $3097,0 \pm 99,1$ & $2854,2 \pm 99,1$ & $2564,7 \pm 99,1$ & $2838,6 \pm 57,2$ & $* *$ & $*$ \\
\hline $0,3 \%$ & $3071,4 \pm 99,1$ & $2806,0 \pm 99,1$ & $2659,6 \pm 99,1$ & $2845,7 \pm 57,2$ & $*$ & $*$ \\
\hline \multirow[t]{2}{*}{ Média } & $3084,2 \pm 70,0$ & $2830,1 \pm 70,0$ & $2612,1 \pm 70,0$ & & $\mathrm{~ns}$ & ns \\
\hline & & EM (kcal/kg) & & & & \\
\hline $0,0 \%$ & $2955,4 \pm 100,4$ & $2729,9 \pm 100,4$ & $2448,0 \pm 100,4$ & $2711,2 \pm 57,9$ & $* *$ & ns \\
\hline $0,3 \%$ & $2922,9 \pm 100,4$ & $2670,9 \pm 100,4$ & $2541,7 \pm 100,4$ & $2711,8 \pm 57,9$ & $*$ & ns \\
\hline \multirow[t]{2}{*}{ Média } & $2939,2 \pm 71,0$ & $2700,4 \pm 71,0$ & $2495,0 \pm 71,0$ & & ns & ns \\
\hline & & CRN (\%) & & & & \\
\hline $0,0 \%$ & $14,66 \pm 4,41$ & $18,10 \pm 4,41$ & $18,64 \pm 4,41$ & $17,13 \pm 2,54$ & $\mathrm{~ns}$ & ns \\
\hline $0,3 \%$ & $19,96 \pm 4,41$ & $14,91 \pm 4,41$ & $26,59 \pm 4,41$ & $20,49 \pm 2,54$ & $\mathrm{~ns}$ & ns \\
\hline \multirow[t]{2}{*}{ Média } & $17,31 \pm 3,12$ & $16,51 \pm 3,12$ & $22,61 \pm 3,12$ & & ns & ns \\
\hline & & Nret (g/dia) & & & & \\
\hline $0,0 \%$ & $5,01 \pm 1,46$ & $6,17 \pm 1,46$ & $6,49 \pm 1,46$ & $5,89 \pm 0,84$ & ns & ns \\
\hline $0,3 \%$ & $7,40 \pm 1,46$ & $4,87 \pm 1,46$ & $9,33 \pm 1,46$ & $7,20 \pm 0,84$ & ns & ns \\
\hline \multirow[t]{2}{*}{ Média } & $6,20 \pm 1,03$ & $5,52 \pm 1,03$ & $7,91,1,03$ & & ns & ns \\
\hline & & Ning (g/dia) & & & & \\
\hline $0,0 \%$ & $34,16 \pm 0,63^{\mathrm{B}}$ & $34,09 \pm 0,63^{A}$ & $35,12 \pm 0,63^{\mathrm{A}}$ & $34,46 \pm 0,37$ & ns & ns \\
\hline $0,3 \%$ & $37,05 \pm 0,63^{\mathrm{A}}$ & $33,73 \pm 0,63^{A}$ & $35,11 \pm 0,63^{\mathrm{A}}$ & $35,30 \pm 0,37$ & $* *$ & ns \\
\hline \multirow[t]{2}{*}{ Média } & $35,60 \pm 0,45$ & $33,91 \pm 0,45$ & $35,12 \pm 0,45$ & & ns & $\mathrm{ns}$ \\
\hline & & Nret/Ning & & & & \\
\hline $0,0 \%$ & $0,029 \pm 0,009$ & $0,036 \pm 0,009$ & $0,037 \pm 0,009$ & $0,03 \pm 0,005$ & ns & $\mathrm{ns}$ \\
\hline $0,3 \%$ & $0,039 \pm 0,009$ & $0,029 \pm 0,009$ & $0,053 \pm 0,009$ & $0,04 \pm 0,005$ & ns & $\mathrm{ns}$ \\
\hline Média & $0,034 \pm 0,006$ & $0,033 \pm 0,006$ & $0,045 \pm 0,006$ & & ns & $\mathrm{ns}$ \\
\hline
\end{tabular}

${ }^{\mathrm{A}, \mathrm{B}}$ Médias seguidas da mesma letra na coluna, não diferem entre si pelo teste $\mathrm{F}(\mathrm{P}<0,05)$; (1) - Controle X Demais; (2) - Alfafa 5\% X Alfafa $10 \%$; ns - não significativo; ** - significativo a 1\%; * significativo a 5\%. CDMS - coeficiente de digestibilidade da matéria seca; CDPB - coeficiente de digestibilidade da proteína bruta; CDEE - coeficiente de digestibilidade do extrato etéreo; CDFDN - coeficiente de digestibilidade da fibra em detergente neutro; CDFDA - coeficiente de digestibilidade da fibra em detergente ácido; CDEB - coeficiente de digestibilidade da energia bruta; CMEB - coeficiente de metabolizabilidade da energia bruta; ED energia digestível; EM - energia metabolizável; CRN - coeficiente de retenção de nitrogênio; Nret - nitrogênio retido; Ning - nitrogênio ingerido; Nret/Ning nitrogênio retido/nitrogênio ingerido. 
Oliveira et. al. (2001), estudando a substituição do milho por níveis de casca de café $(0,5,10$ e $15 \%)$ para leitões em crescimento, verificaram redução linear $(\mathrm{P}<0,05)$ em todas as varáveis estudadas no ensaio de metabolismo, o principal fator que pode ter influenciado estes resultados é o teor de FDN das dietas $(10,93 ; 13,07 ; 15,20$; $17,32 \%$, respectivamente). A redução linear $(\mathrm{P}<0,01)$ nos valores de ED e EM que estes autores obtiveram com $\mathrm{O}$ aumento de casca de café, concorda com os resultados do presente estudo, porém, considerando-se que as rações foram formuladas para serem isoenergéticas, esses resultados não eram esperados. As explicações para as respostas observadas possivelmente estão relacionadas com uma superestimativa dos valores de ED da casca de café.

Diferentemente da redução dos coeficientes de digestibilidade dos outros nutrientes o coeficiente de digestibilidade do extrato etéreo apresentou aumento significativo $\quad(\mathrm{P}<0,01) \quad$ quando comparadas as dietas sem inclusão de fibra com os tratamentos 5 ou $10 \%$ de alfafa, e também estes entre si. Esse aumento pode ser justificado pela maior inclusão de óleo nas dietas de maior teor de fibra dietética, para que se atingissem os níveis de energia digestível adequado. Nascimento (2009) trabalhando com inclusão de diferentes níveis de farelo de algodão para suínos relatou aumento significativo $(\mathrm{P}<0,05)$ para os coeficientes de digestibilidade do extrato etéreo à medida que aumentou o nível de inclusão deste ingrediente de 20 para $30 \%$. Resultados diferentes destes foram observados por Pascoal et al. (2012) que relatou piora no coeficiente de digestibilidade do extrato etéreo em dietas com a inclusão de casca de soja e polpa cítrica para leitões de $13 \mathrm{~kg}$. Explica o autor que, principalmente a fração solúvel da fibra pode reduzir a digestão de lipídeos, por influenciar diretamente a viscosidade da digesta, inibindo a hidrólise e solubilização deste nutriente. Isto pode explicar a menor digestibilidade da gordura quando da inclusão de FOS nas dietas controle e 5\% de alfafa.

Quanto ao balanço nitrogenado, foi verificado aumento na quantidade de nitrogênio ingerido quando comparada a dieta controle com os tratamentos 5 e 10 $\%$ de feno de alfafa, na presença do prebiótico. Porém não foram encontradas diferenças significativas $(\mathrm{P}>0,05)$ para $\mathrm{o}$ coeficiente de retenção de nitrogênio, quantidade de nitrogênio retido e a relação entre retido e ingerido. Segundo Pascoal et al. (2012), a presença de fibra na dieta modifica a rota de excreção de $\mathrm{N}$, sem alterar significativamente a sua retenção. Os resultados de Oliveira et. al. (2001) discordam dos obtidos no presente estudo, pois trabalhando com diferentes níveis de casca de café, encontraram redução linear $(\mathrm{P}<0,05)$ na quantidade de nitrogênio retido, estes autores justificaram esses resultados pela redução no consumo de nitrogênio e energia, com o aumento de casca de café na ração.

Concluiu-se que a inclusão de FOS incrementou o consumo de dietas ricas em alfafa. A adição do feno de alfafa reduziu os coeficientes de digestibilidade dos nutrientes com exceção do extrato etéreo, porém não influenciou o balanço do nitrogênio.

\section{AGRADECIMENTOS}

À Fundação de Amparo à Pesquisa do Estado de São Paulo (FAPESP) pelo auxílio à pesquisa e pela bolsa de mestrado. À empresa Corn Products do Brasil pelo fornecimento do produto FortiFeed $\AA$. 
Rev. Bras. Saúde Prod. Anim., Salvador, v.16, n.4, p.796-810 out../dez.., 2015 http://www.rbspa.ufba.br ISSN 15199940

\section{REFERÊNCIAS}

ASSOCIATION OF OFFICIAL ANALITICAL CHEMISTS - AOAC. Official Methods of Analysis. 12.ed. Washington: Willian Horwitz, 1975. 1094p.

BINDELE, J.; LETERME, P.; BULDGEN, A. Nutritional and environmental consequences of dietary fibre in pig nutrition: a review.

Biotechnology Agronomy Society and Environment, v.12, p.69-80, 2008.

BUDIÑO, F.E.L.; CASTRO JUNIOR, F.G.; OTSUK, I.P. Adição de

frutoligossacarídeo em dietas para leitões desmamados: desempenho, incidência de diarreia e metabolismo.

Revista Brasileira de Zootecnia, v.39, n.10, p.2187-2193, 2010.

BUDIÑO, F.E.L.; THOMAZ, M.C.; KRONKA, R.N.; TUCCI, F.M.; FRAGA, A.L.; SCANDOLERA, A.J.; ROBLES - HUAYNATE, R.A;

NADAI, A.; CORREIA, R.C. Efeito da adição de probiótico e/ou prebiótico em dietas de leitões desmamados sobre o desempenho, incidência de diarréia e contagem de coliformes totais.

Brazilian Journal of Veterinary Research and Animal Science, v.43, p.59-67, 2006.

GOMES, J.D.F.; PUTRINO, S.M.; MARTELLI, M.R.; SOBRAL, P.J.A.; FUKUSHIMA, R.S. Desempenho e características de carcaça de suínos alimentados com dieta com feno de tifton (Cynodon Dactylon). Ciência Animal Brasileira, v.9, n.1, p.59-67, 2008.
HE, G.; BAIDOO, S.K.; YANG, Q.; GOLZ, D.; TUNGLAND, B. Evaluation of chicory inulin extracts as feed additive for early-weaned pigs. Journal Animal Science, v.80, p.81-91, 2002.

HÖGBERG, A.; LINDBERG, J.E. Influence of cereal non-starch polysaccharides and enzyme supplementation on digestion site and gut environment in weaned piglets.

Animal Feed Science Technology, v.116, p.113-128, 2004.

HOUDIJK, J.G.M.; BOSCH, M.W.; VERSTEGEN, M.W.A.; BERENPAS, H.J. Effects of dietary oligosaccharides on the growth performance and faecal characteristics of young growing pigs. Animal Feed Science Technology, v.71, p.35-48, 1998.

HUO, G.C. Utilization of fibrous materials by the indigenous breed of pigs (Northeast mini pig). 1. Effects of dietary fibre on performance and backfat thickness. Pig News and Information, v.14, p.273, 1993.

LONGLAND, A.C.; CARRUTHERS, J.; LOW, A.G. The ability of piglets 4 to 8 weeks old to digest and perform on diets containing two contrasting sources of non-starch polysaccharide. Animal Science, v.58, n.3, p.405-410, 1994.

McDONALD, P.; EDWARDS, R.A.; GREENHALGH, J.F.D.; MORGAN, C.A. Nutrición animal. 6.ed. Zaragoza: Acribia, 2006. 587p.

MIKKELSEN, L.L.; JAKOBSEN, M.; JENSEN, B.B. Effects of dietary oligossaccharides on microbial diversity and fructo-oligossaccharide degrading bacteria in faeces of piglets postweaning. Animal Feed Science Technology, v.109, n.1/4, p.133-150, 2003. 
Rev. Bras. Saúde Prod. Anim., Salvador, v.16, n.4, p.796-810 out../dez.., 2015 http://www.rbspa.ufba.br

MOLIST, F.; GÓMES DE SEGURA, A.; GASA, J.; HERMES, R.G.; MANZANILLA, E.G.; ANQUITA, M.; PÉREZ, J.F. Effects of the insoluble and soluble dietary fibre on the physicochemical properties of digesta and microbial activity in early weaned piglets. Animal Feed Science

Technology, v.149, p.346-353, 2009.

NASCIMENTO, C.L.M.M. do.

Avaliação de desempenho de suínos nas fases de crescimento e terminação alimentados com farelo de algodão de alta energia. In: REUNIÃO ANUAL DA SOCIEDADE BRASILEIRA DE ZOOTECNIA, 46, 2009, Maringá. Anais..., Maringá: SBZ, 2009.

OLIVEIRA, V.; FIALHO, E.T.; LIMA, J.A.F.; OLIVEIRA, A.I.G.; FREITAS, R.T.F. Substituição do milho por casca de café em rações isoenergéticas para suínos em crescimento e terminação.

Ciência e Agrotecnologia, v.25, n.2, p.424-436, 2001.

PASCOAL, L.A.F.; THOMAZ, M.C.; WATANABE, P.H; RUIZ, U.S.; EZEQUIEL, J.M.B.; DANIEL, E.; AMORIM, A.B.; MASSON, G.C.I.

Fiber sources in diets for newly weaned piglets. Revista Brasileira de

Zootecnia, v.41, p.636-642, 2012.

ROBLES-HUAYNATE, R.A.; THOMAZ, M.C.; SANTANA, A.E.; MASSON, G.C.I.H.; AMORIM, A.B.; SILVA, S.Z.; RUIZ, U. dos S.; WATANABE, P.H.; BUDIÑO, F.E.L. . Efeito da adição de probiótico em dietas de leitões desmamados sobre as características do sistema digestório e de desempenho. Revista Brasileira de Saúde e Produção Animal [online], v.14, p.248-258, 2013.
ROSTAGNO, H.S.; ALBINO, L.F.T.; DONZELE, J.L.; GOMES, P.C.; OLIVEIRA, R.F.; LOPES, D.C.; FERREIRA, A.S., BARRETO, S.L.T.

Tabelas brasileiras para aves $\mathrm{e}$ suínos: Composição de alimentos e exigências nutricionais. Viçosa, MG: Universidade Federal de Viçosa, 2011. $252 \mathrm{p}$.

SAKOMURA, N.K.; ROSTAGNO, H.S. Métodos de pesquisa em nutrição de monogástricos. Jaboticabal: FUNEP, 2007. 283p.

SANTOS, Z.A.S.; FREITAS, R.T.F.; FIALHO, E.T.; RODRIGUES, P.B.; LIMA, J.A.F.; CARELLOS, D.C.; BRANCO, P.A.C.; CANTARELLI, V.S. Valor nutricional de alimentos para suínos determinados na Universidade Federal de Lavras. Ciência e Agrotecnologia, v.29, n.1, p.232-237, 2005.

SERENA, A.; HEDEMANN, M.S.; BACH KNUDSEN, K.E. Influence of dietary fiber on luminal environment and morphology in the small and large intestine of sows. Journal Animal Science, v.86, p.2217-2227, 2008.

Data de recebimento: 04/02/2014

Data de aprovação: 29/10/2015 